\title{
El estudio del desarrollo en niños pequeños a partir de dos dominios: comprensión de acciones y comprensión simbólica
}

\author{
Eva Jauck \\ Olga Alicia Peralta \\ Instituto Rosario de Investigaciones en Ciencias de la Educación- \\ Consejo Nacional de Investigaciones Científicas y Técnicas, \\ Argentina
}

Recibido: 18 de febrero del 2018 / Aceptado: 4 de febrero del 2019 doi: 10.26439/persona2019.n022(1).4081

El objetivo del trabajo consiste en ilustrar una nueva forma de aproximación al estudio del desarrollo cognitivo a partir de investigaciones en dos dominios de conocimiento que han permanecido escindidos: la comprensión de acciones y la comprensión simbólica de imágenes. Primero, se muestran recientes investigaciones en niños pequeños sobre la comprensión de acciones a través de las acciones en vivo y las acciones en imágenes. Luego, se incluye la comprensión simbólica temprana tanto de imágenes en general como las provistas por una tablet. Por último, se presentan trabajos que han unido ambos caminos al estudiar la comprensión simbólica de imágenes que representan acciones, por parte de niños (desde dos años en adelante).

dominio de conocimiento / comprensión simbólica / comprensión de acciones

\section{Studying the development of young children from two domains: action and symbolic understanding}

This paper aims to illustrate a novel approach to the study of cognitive development by researching two domains of knowledge that have remained separated: action understanding and symbolic understanding of images. First, we show recent research on young children's action understanding through live actions and actions in images. Then, we address young children's early symbolic understanding of images in general and digital images displayed in a tablet. Finally, we present some studies that have linked both paths by analyzing the symbolic understanding of images that represent real actions in children aged 2 or older.

\section{domains of knowledge / symbolic understanding / action understanding}

Correo electrónico: jauck@irice-conicet.gov.ar 


\section{INTRODUCCIÓN}

Desde hace ya varios años se ha suscitado un debate en relación con la distinción entre dominios de conocimiento general y específico. Los investigadores se han preguntado hasta qué punto la mente es de dominio general o si es, por el contrario, una colección de sistemas especializados en diferentes dominios de conocimiento (Hirschfeld y Gelman, 2002; KarmiloffSmith, 1994). En la actualidad, se ha alcanzado un consenso respecto de que la mente es una herramienta que puede cumplir tareas de diversa índole en distintos momentos. En este sentido, la psicología del desarrollo no se conforma solo con describir qué hacen los seres humanos a qué edades en áreas específicas, sino que busca explicar cómo funciona la mente humana.

Actualmente, se pueden encontrar numerosas investigaciones en diferentes dominios que permiten pensar en diversos caminos en el estudio de la cognición. Tomando como base investigaciones en dos dominios que han permanecido escindidos: la comprensión de acciones y la comprensión simbólica de imágenes, este trabajo tiene por objetivo ilustrar el abordaje del desarrollo cognitivo a partir de investigaciones que unen ambos caminos al estudiar la comprensión simbólica de imágenes que representan acciones que ocurren en la realidad.

Para poder dar cuenta de ello, en este trabajo primero se presentan estudios enfocados en la comprensión de acciones en niños muy pequeños a partir de nuevos paradigmas en la investigación en psicología del desarrollo. Luego, se expone la comprensión temprana de la función de representación de objetos simbólicos, específicamente de imágenes tanto impresas como digitales. Finalmente, se discuten investigaciones que intentan unir ambos caminos al estudiar la comprensión simbólica, por parte de niños pequeños, de imágenes que representan acciones que ocurren en la realidad.

\section{LA COMPRENSIÓN DE ACCIONES}

Tradicionalmente, los estudiosos del desarrollo han mostrado a los bebés como seres que se encuentran en un estado inicial de confusión. Por ejemplo, William James (1842-1910) consideró que los bebés no muestran signos claros de distinguir entre el estímulo del propio yo y los externos. Por su parte, Piaget (1952) afirmó que las modalidades de los sentidos funcionan como sistemas independientes o autónomos en las primeras fases de la vida, y solo con el paso de tiempo se organizan y coordinan para ofrecer una percepción unificada del mundo.

Sin embargo, como señalan algunos autores (Karmiloff-Smith, 1994; Rochat, 2004; Tomasello, 2008), desde la década de 1960 estudios observacionales y experimentales han revelado que los bebés desde los primeros momentos poseen capacidades cognitivas que no son fáciles de detectar en su conducta visible. Para ello, numerosas investigaciones se han valido de habilidades como chupar, seguir los objetos con la mirada, dar patadas u orientar la cabeza; y de respuestas fisiológicas, como el ritmo circadiano o actividades eléctricas del cerebro (Corbetta, Guan y Williams, 
2012; Hamlin, Hallinan y Woodward, 2008; Onishi y Baillargeon, 2005).

Muchas de las primeras acciones de los bebés se orientan hacia el propio cuerpo, como chupar los dedos o llevar objetos hacia la boca. Esta autoexploración les permite adquirir conocimiento sobre sus propias acciones y, conforme avanza su desarrollo, sobre las acciones de los otros (Blass, Fillion, Rochat, Hoffmeyer y Metzger, 1989; Rochat, 2004). De esta forma, los niños desde muy pequeños se encuentran fascinados con los efectos que producen sus acciones y desarrollan expectativas sobre los posibles resultados. Una vez que se adaptan a las contingencias de la retroalimentación intermodal, pasan a desarrollar intereses sociales, desplazando hacia los demás una atención que antes solo estaba orientada a sí mismos (Rochat, 2004; Stern, 1985; Tomasello, 2008).

La comprensión de las acciones de otros les resulta esencial a los niños para que puedan dar sentido al mundo circundante. Muy temprano en la vida, los niños comprenden las acciones realizadas por otros y las interpretan en función de relaciones dirigidas hacia un fin (Baldwin, Baird, Saylor y Clark, 2001; Barresi y Moore, 1996; Woodward, 1998; Woodward, Sommerville, Gerson, Henderson y Buresh, 2009). Es decir, cuando los niños observan acciones, no ven simples movimientos en el espacio, sino movimientos organizados entre agentes y objetivos en contextos específicos (Woodward y Gerson, 2014). Aún más, si los agentes son humanos (por ejemplo, un brazo versus una garra mecánica), los bebés captan con más facilidad el movimiento como algo dirigido hacia un objetivo (Cannon y Woodward, 2010; Jovanovic et al., 2007; Woodward, 1998).

Por otro lado, se ha sugerido que la experiencia propia no es la única ruta hacia la comprensión de las acciones de otros. Así, los bebés pueden asociar eventos rápidamente (Slater, Quinn, Brown y Hayes, 1999), tomar información a través de múltiples ocurrencias y extraer patrones estadísticos a partir de observaciones repetidas (Kirkham, Slemmer y Johnson, 2002). En la vida cotidiana, los niños tienen muchas oportunidades para formar asociaciones entre los eventos observados y aprender sobre las regularidades estadísticas de comportamiento de otros. Desde la experiencia activa y observacional, los niños van adquiriendo una comprensión gradualmente más compleja sobre las acciones de otros (Hunnius y Bekkering, 2014; Stapel, Hunnius, Van Elk y Bekkering, 2010).

Los estudios sobre comprensión de acciones de otros dirigidas hacia un fin, por parte de bebés y niños pequeños, en su gran mayoría se efectuaron con secuencias presentadas en imágenes de video; el niño las observaba y luego debía anticipar el resultado de la acción. Se utilizaron técnicas tales como la mirada preferencial (Saylor, Baldwin, Baird y LaBounty, 2007; Woodward, 1998) o el seguimiento visual (Falck-Ytter, Gredebäck y Von Hofsten, 2006; Flanagan y Johansson, 2003). La finalidad de esos estudios es la comprensión de la acción en sí misma, y no si el video representa una acción que tiene lugar en la realidad. 
Al respecto, Falck-Ytter et al. (2006) utilizaron la técnica de seguimiento visual para enseñar a bebés de 12 meses imágenes de videos en las que una persona colocaba pelotas pequeñas en un recipiente mostraron que los bebés predicen el resultado de las acciones antes de que estas se completen.

Por su parte, Baldwin et al. (2001) demostraron que bebés de 11 meses podían extraer información de acciones grabadas en video cuando estas acciones eran desarrolladas de manera continua y en secuencias coincidentes con los límites de los objetivos e intenciones de un actor. Este estudio mostró que los bebés detectan las interrupciones de las estructuras inherentes a la acción, lo que resulta disruptivo para la comprensión de la acción.

También se ha demostrado que los bebés o los niños pequeños no encuentran dificultades en la comprensión de acciones en vivo. Por ejemplo, Woodward (1998) habituó a bebés de tan solo 6 meses a que observaran una escena en la que un brazo tomaba uno de dos juguetes (pelota y oso de peluche). Luego, los bebés veían nuevamente los dos objetos, pero esta vez se introducía un cambio, ya sea en la trayectoria del movimiento del brazo o en la posición del objeto. Los resultados mostraron que los niños se sorprenden cuando cambia el objetivo, pero no cuando cambia la trayectoria del movimiento del brazo. Estos resultados sugieren que los bebés interpretan que las acciones de otras personas van dirigidas a objetivos, y no solo son movimientos en el espacio.

Los estudios revisados evidencian que la comprensión de acciones está presente desde muy temprana edad y resulta más sencilla cuando las acciones son desempeñadas de manera continua y en secuencias coincidentes con los límites de las intenciones del actor.

La comprensión de acciones cobra un nuevo sentido cuando los niños comienzan a participar en interacciones tríadicas e incluyen la coordinación de interacciones con objetos y personas, lo que da por resultado un triángulo referencial constituido por el niño, el adulto y el objeto o acontecimiento (Carpenter, Nagell, Tomasello, Butterworth y Moore, 1998).

\section{LA COMPRENSIÓN DE IMÁGENES COMO OBJETOS SIMBÓLICOS}

Las imágenes son objetos simbólicos que se caracterizan por poseer una doble realidad, ya que tienen características físicas propias y, al mismo tiempo, son símbolos de la entidad que representan (DeLoache, 2004). La naturaleza y propiedades de este tipo de objetos hacen que su utilización como medios simbólicos sea un verdadero desafío para los niños pequeños, lo que explica que su adquisición sea más tardía que la de otros medios comunicativos, como los gestos y el lenguaje.

Se ha propuesto que el origen de las dificultades para comprender la función representacional de un objeto simbólico puede explicarse a partir de su doble realidad (DeLoache, 2004). Para captar la función de representación de un objeto simbólico, es necesario mantener dos representaciones mentales activas en simultáneo, la del objeto en sí mismo y la de la entidad que representa, y establecer relaciones entre 
una y otra. Es decir, para comprender una imagen de forma simbólica, se debe reconocer su contenido en sí mismo y, además, entender su función de referencia.

El impacto de esta doble representación fue testeado en numerosas investigaciones utilizando una prueba de búsqueda (DeLoache, 1987; DeLoache, Kolstad y Anderson, 1991). La tarea de búsqueda clásica consiste en un juego sencillo en el que los niños observan a un experimentador esconder un juguete en miniatura en un lugar específico de una maqueta (por ejemplo, debajo de un sillón) que representa una habitación real contigua, amueblada como la sala de una casa. Luego, se le pide al niño que encuentre un juguete similar, pero de mayor tamaño (escondido por el experimentador sin ser visto por el niño), en el lugar correspondiente de la habitación real. Si el niño reconoce la relación símbolo-referente, podrá utilizar la información que obtuvo del objeto simbólico (la maqueta) para encontrar el juguete en la habitación real. Si el niño no capta la función simbólica del objeto, esa información no le será útil en su búsqueda.

Se ha propuesto que la tridimensionalidad de un objeto simbólico afecta su accesibilidad simbólica, al acentuar sus propiedades como objeto en detrimento de sus propiedades como símbolo (DeLoache, 1987). En este sentido, se ha postulado que la tarea de búsqueda debería simplificarse si se utiliza una imagen. A pesar de que una imagen es también un objeto concreto, típicamente no tiene rol alguno más que el de ser la representación de otra cosa. Incluso, se ha demostrado que manipular un objeto simbólico, por ejemplo, jugar con la maqueta, aumenta sus propiedades como objeto concreto en detrimento de su función simbólica (Uttal, O’Doherty, Newland, Hand y DeLoache, 2009; Tare, Chiong, Ganea y DeLoache, 2010).

En una serie de estudios (DeLoache, 1987, 1991; DeLoache y Burns, 1994), la información acerca de la ubicación del juguete escondido fue transmitida por medio de una fotografía y la predicción fue que la ejecución de los niños mejoraría. Los resultados corroboraron esto. Con la utilización de fotografías y dibujos, se encontró que a los 30 meses los niños resuelven la tarea; mientras que con una maqueta, a los 36. En cuanto a la manipulación, en tareas sobre aprendizaje de palabras se observó que si se acentúan las propiedades físicas de una imagen, por ejemplo, presentarles un libro con ilustraciones desplegables y manipulables, los niños manifiestan dificultades para establecer la relación símbolo-referente, en comparación con los libros estándares (Tare et al., 2010).

En el caso de imágenes mostradas en pantallas táctiles, Sheehan y Uttal (2016) han señalado que si bien las investigaciones en representación dual sugieren que las propiedades manipulativas de las pantallas táctiles pueden dificultar el uso de sus imágenes como medios simbólicos, las propiedades interactivas de estos dispositivos podrían ayudar a superar esta dificultad. Aunque se ha señalado que las experiencias interactivas o no interactivas de las pantallas táctiles tienen efectos diferenciales en el aprendizaje infantil, aún no se han realizado estudios que examinen sistemáticamente 
estos supuestos (Kirkorian, Choi y Pempek, 2016; Troseth, Russo, y Strousse, 2016).

Siguiendo esta línea, en estudios recientes se han utilizado tareas de búsqueda para explorar la comprensión y usos simbólicos de imágenes captadas y producidas por un dispositivo táctil en particular, una tablet. En estos estudios se ha encontrado que este tipo de imágenes poseen algunas ventajas en cuanto a su accesibilidad simbólica, ya que permiten destacar la relación entre el símbolo y el referente, haciendo más explícita su función de referencia. Producir en forma instantánea una imagen que permanece en la pantalla probablemente favorece el establecimiento de correspondencias entre los elementos de la realidad y de la imagen, la comprensión de la intención de representación por parte del usuario. Correspondencia e intencionalidad son dos mecanismos claves en la comprensión simbólica.

En cuanto a la correspondencia, investigaciones sobre razonamiento analógico respaldan que el proceso de comparación, el cual involucra mapeo y alineamiento estructural punto a punto, provee un insight en procesos cognitivos más profundos (Gentner y Markman, 1997; Gentner y Namy, 1999; Namy y Gentner, 2002; Lowenstein y Gentner, 2001).

Respecto de la intencionalidad, se ha demostrado que captar el propósito con que se está empleando una herramienta resulta fundamental para el desempeño en una tarea simbólica (Roseberry, HirshPasek y Golinkoff, 2014). Después de todo, una imagen es informativa en una tarea solo porque el experimentador así lo propone. Por tanto, una parte importante de la comprensión de la relación símboloreferente por parte del niño incluye el reconocimiento de la intención del adulto en utilizarla (Bloom y Markson, 1998; Gelman y Ebeling, 1998).

\section{ESTUDIO DE LA COMPRENSIÓN SIMBÓLICA} DE IMÁGENES QUE REPRESENTAN ACCIONES

En la vida cotidiana, los niños observan imágenes estáticas o dinámicas en libros impresos, televisión, videos, pantallas táctiles, etcétera, y muchas veces disfrutan de las acciones que muestran; pero ¿comprenden que esas imágenes representan acciones que ocurren o que pueden ocurrir en la realidad?

Las investigaciones revisadas han aportado importante información sobre la comprensión de acciones vistas en imágenes o en vivo. Sin embargo, en estas investigaciones no se ha indagado si los niños comprenden que estas imágenes refieren a acciones reales. Para ello, los niños deben tomar las imágenes en forma simbólica.

Un estudio precursor que unió la comprensión de acciones con la comprensión simbólica de imágenes que las representan fue el de Harris, Kavanaugh y Dowson (1997). Estos autores indagaron acerca de la utilización de una imagen para comunicar información de acciones efectuadas sobre un objeto real. En esta investigación, un experimentador llevó a cabo acciones reales o imaginarias sobre determinados objetos, por ejemplo, hacía como si ensuciaba un juguete, o lo 
ensuciaba, vertiéndole una salsa. Luego, pedía a los niños que seleccionaran una fotografía (entre tres) que mostraba el resultado de la acción. Los niños menores de 28 meses seleccionaron al azar, pero los mayores fueron muy exitosos al escoger la imagen que representaba el resultado de la acción. Este estudio evidenció que los niños no solo comprendían la acción, sino que tomaban las imágenes en forma simbólica como una representación de la realidad. Resulta interesante destacar que en este estudio la acción siempre fue la misma, ensuciar, y al repetirse la acción no se descartaron posibles efectos de aprendizaje o familiaridad con la acción específica a lo largo de la prueba.

Por su parte, en un estudio reciente se exploró si niños de 24, 30 y 36 meses de edad comprenden simbólicamente imágenes provistas por una tablet como representaciones de acciones dirigidas hacia un fin. Las autoras diseñaron una tarea en la que los niños observaban diferentes secuencias de acciones (por ejemplo, romper un papel, cortar una manzana, ensuciar un oso de peluche con pintura), y las imágenes mostraban la secuencia, pero no el resultado final. Luego de observar cada secuencia, el niño debía elegir el resultado de la acción escogiendo una de tres opciones: (1) objeto con la modificación correcta, (2) objeto sin modificación alguna, (3) objeto con otra modificación. Los resultados mostraron que los niños de 30 y 36 meses, a diferencia de los de 24 , comprendieron que las secuencias de imágenes se referían a una acción que tenía lugar en la realidad, ya que escogieron el objeto real que mostraba el resultado de la acción. Aunque podría pensarse que los niños más pequeños fallaron en la tarea debido a que no comprendieron las acciones representadas, las autoras argumentaron que no fue el caso, ya que frecuentemente verbalizaban las acciones al observar las secuencias; por ejemplo, “Está cortando" (manzana), "Está abriendo una carta" (papel).

Las dificultades de los niños dan cuenta de que el mayor inconveniente no se relaciona con la comprensión de las acciones, sino con la imposibilidad de entender la naturaleza dual de las imágenes que las representan, es decir, que refieren a hechos de la realidad.

\section{CONCLUSIONES}

Si bien los niños desde muy pequeños comprenden acciones de diferente naturaleza en sí mismas, un logro importante consiste en entender que las imágenes que las representan pueden comunicar acciones que ocurren en el mundo.

Las investigaciones revisadas en este trabajo muestran, por un lado, que la comprensión de acciones dirigidas hacia un fin se manifiesta tempranamente en el desarrollo; por otro, que la comprensión simbólica de imágenes emerge más tardíamente, hacia el final del segundo año de vida. Esta adquisición es sumamente desafiante y compleja, ya que requiere de una cierta flexibilidad cognitiva que permita ver a través del símbolo a su referente. Por último, estudios que han unido ambas vertientes (Harris et al., 1997) dan cuenta de cómo la ciencia psicológica puede 
pensar en el desarrollo cognitivo desde una perspectiva más integral.

Este trabajo ilustra una nueva forma de abordar el estudio del desarrollo simbólico en niños pequeños, a partir de dos dominios de conocimiento en la psicología del desarrollo: la comprensión simbólica de imágenes y la comprensión de acciones. Consideramos que este tipo de abordaje permite avanzar en el estudio y explicación de los cambios que se producen en el desarrollo temprano, y entender el desarrollo cognitivo temprano de una forma integrada.

\section{RefERENCIAS}

Baldwin, D. A., Baird, J. A., Saylor, M. M., y Clark, M. A. (2001). Infants Parse Dynamic Action. Child Development, 72(3), 708-7.

Barresi, J., y Moore, C. (1996). Intentional Relations and Social Understanding. Behavioral and Brain Sciences, 19, 107-154.

Blass, E. M., Fillion, T. J., Rochat, P., Hoffmeyer, L. B., y Metzger, M. A. (1989). Sensorimotor and Motivational Determinants of Hand-Mouth Coordination in 1-3-Day Old Human Infants. Developmental Psychology, 25(6), 963-975.

Bloom, P., y Markson, L. (1998). Intention and Analogy in Children's Naming of Pictorial Representations. Psychological Science, 9(3), 200-204.

Cannon, E., y Woodward, A. L. (marzo de 2010). Familiar Actions Trump "Action-Effects" in Goal Detection in the First Year. Trabajo presentado en la International Conference on Infant Studies. Baltimore, MD.

Carpenter, M., Nagell, K., Tomasello, M., Butterworth, G., y Moore, C. (1998). Social Cognition, Joint Attention, and Communicative Competence from 9 to 15 Months of Age. Monographs of the Society for Research in Child Development, i-174.

Corbetta, D., Guan, Y., y Williams, J. L. (2012). Infant Eye-Tracking in the Context of Goal-Directed Actions. Infancy, 17(1), 102-125.

DeLoache, J. S. (1987). Rapid Change in the Symbolic Functioning of Very Young Children. Science, 238(4833), 1556-1557.

DeLoache, J. S. (1991). Symbolic Functioning in Very Young Children: Understanding of Pictures and Models. Child Development, 62(4), 736-752.

DeLoache, J. S. (2004). Becoming Symbol-Minded. Trends in Cognitive Sciences, 8(2), 66-70.

DeLoache, J. S., y Burns, N. M. (1994). Early Understanding of the Representational Function of Pictures. Cognition, 52(2), 83-110.

DeLoache, J. S., Kolstad, V., y Anderson, K. N. (1991). Physical Similarity and Young Children's Understanding of Scale Models. Child Development, 62(1), 111-126. 
Falck-Ytter, T., Gredebäck, G., y Von Hofsten, C. (2006). Infants Predict other People's Action Goals. Nature Neuroscience, 9(7), 878-879.

Flanagan, J. R., y Johansson, R. S. (2003). Action Plans Used in Action Observation. Nature, 424(6950), 769-771.

Gelman, S. A., y Ebeling, K. S. (1998). Shape and Representational Status in Children's Early Naming. Cognition, 66(2), B35-B47.

Gentner, D., y Markman, A. (1997). Structure Mapping in Analogy and Similarity. American Psychologist, 52, pp. 45-56.

Gentner, D., y Namy, L. L. (1999). Comparison in the Development of Categories. Cognitive Development, 14(4), 487-513.

Hamlin, J. K., Hallinan, E. V., y Woodward, A. L. (2008). Do As I Do: 7-Month-Old Infants Selectively Reproduce Others' Goals. Developmental Science, 11(4), 487-494.

Harris, P. L., Kavanaugh, R. D., y Dowson, L. (1997). The Depiction of Imaginary Transformations: Early Comprehension of a Symbolic Function. Cognitive Development, 12(1), 1-19.

Hirschfeld, L., y Gelman, S. (2002). Hacia una topografía de la mente: introducción a la especificidad de dominio. En L. Hirschfeld y S. Gelman (Eds.), Cartografía de la mente. La especificidad de dominio en la cognición y en la cultura (pp. 23-67). Barcelona: Gedisa.

Hunnius, S., y Bekkering, H. (2014). What Are you Doing? How Active and Observational Experience Shape Infants' Action Understanding. Phil. Trans. R. Soc. B, 369(1644), 20130490.

Jovanovic, B., Király, I., Elsner, B., Gergely, G., Prinz, W., y Aschersleben, G. (2007). The Role of Effects for Infants' Perception of Action Goals. Psychologia, 50(4), 273-290.

Karmiloff-Smith, A. (1994). Más allá de la modularidad: La ciencia cognitiva desde la perspectiva del desarrollo. Madrid: Alianza.

Kirkham, N. Z., Slemmer, J. A., y Johnson, S. P. (2002). Visual Statistical Learning in Infancy: Evidence for a Domain General Learning Mechanism. Cognition, 83(2), B35-B42.

Kirkorian, H. L., Choi, K., y Pempek, T. A. (2016). Toddlers' Word Learning from Contingent and Noncontingent Video on Touch Screens. Child Development, 87(2), 405-413.

Lowenstein, J., y Gentner, D. (2001). Spatial Mapping in Preschoolers: Close Comparisons Facilitate Far Mappings. Journal of Cognition and Development, 2(2), 189-219.

Namy, L. L., y Gentner, D. (2002). Making a Silk Purse Out of Two Sow's Ears: Young Children's Use of Comparison in Category Learning. Journal of Experimental Psychology: General, 131(1), 5.

Onishi, K. H., y Baillargeon, R. (2005). Do 15-Month-Old Infants Understand False Beliefs? Science, 308(5719), 255-258. 
Piaget, J. (1952). The Origins of Intelligence in Children. New York: International Universities Press.

Rochat, P. (2004). El mundo del bebé. Madrid: Morata.

Roseberry, S., Hirsh-Pasek, K., y Golinkoff, R. M. (2014). Skype Me! Socially Contingent Interactions Help Toddlers Learn Language. Child Development, 85(3), 956-70.

Saylor, M. M., Baldwin, D. A., Baird, J. A., y LaBounty, J. (2007). Infants' on-Line Segmentation of Dynamic Human Action. Journal of Cognition and Development, $8(1), 113-128$.

Sheehan, K. J., y Uttal, D. H. (2016). Children's Learning from Touch Screens: a Dual Representation Perspective. Frontiers in Psychology, 7.

Slater, A., Quinn, P. C., Brown, E., y Hayes, R. (1999). Intermodal Perception at Birth: Intersensory Redundancy Guides Newborn Infants' Learning Of Arbitrary Auditory-Visual Pairings. Developmental Science, 2(3), 333-338.

Stapel, J. C., Hunnius, S., van Elk, M., y Bekkering, H. (2010). Motor Activation During Observation of Unusual Versus Ordinary Actions in Infancy. Social Neuroscience, 5(5-6), 451-460.

Stern, D. N. (1985). The Interpersonal World of the Infant: A View from Psychoanalysis and Developmental Psychology. London: Karnac Books.

Tare, M., Chiong, C., Ganea, P., y DeLoache, J. (2010). Less Is More: How Manipulative Features Affect Children's Learning from Picture Books. Journal of Applied Developmental Psychology, 31(5), 395-400.

Tomasello, M. (2008). Origins of Human Communication. Cambridge, MA: MIT Press.

Troseth, G. L., Russo, C. E., y Strouse, G. A. (2016). What's Next for Research on Young Children's Interactive Media? Journal of Children and Media, 10(1), 54-62.

Uttal, D. H., O’Doherty, K., Newland, R., Hand, L. L., y DeLoache, J. (2009). Dual Representation and the Linking of Concrete and Symbolic Representations. Child Development Perspectives, 3(3), 156-159.

Woodward, A. L. (1998). Infants Selectively Encode the Goal Object of an Actor's Reach. Cognition, 69(1), 1-34.

Woodward, A. L., y Gerson, S. A. (2014). Mirroring and the Development of Action Understanding. Phil. Trans. R. Soc. B.: Biological Sciences, 369, 20130181.

Woodward, A. L., Sommerville, J., Gerson, S. A., Henderson, A. M. E., y Buresh, J. (2009). The Emergence of Intention Attribution in Infancy. En B. Ross (Ed.). The Psychology of Learning and Motivation (pp. 187-222). Waltham MA: Academic Press. 